\title{
IOT IN TELEMEDICINE-REVIEW ON SMART HEALTH CARE MONITORING SYSTEM WITH PERSONALIZED TREATMENT
}

\author{
Sharon Chris Hepzebah $\mathbf{P}^{1}$, Devaroshini $\mathrm{A}^{\mathbf{2}}$, Navya C Prakash ${ }^{3}$, Sandhiya $\mathrm{A}^{4}$ and Sneha $\mathbf{P}^{5}$ \\ ${ }^{1}$ Faculty, Department of Biomedical Engineering, Bannari Amman Institute of Technology, \\ Erode, Tamilnadu-638401, India. \\ 2,3,4,5 B.E Student, Department of Biomedical Engineering, Bannari Amman Institute of Technology, \\ Erode, Tamilnadu-638401, India.
}

\begin{abstract}
Our contemporary technology is developing unstoppably and reaping rewards in the healthcare domain through telemedicine and mobile health. Telemedicine is a platform that sets up an establishment between the affected person and the healthcare specialist. This platform belongs to net of clinical matter, IoMT (Internet of Medical Things) which uses numerous clinical sensors to associate with the server utilizing a couple of conversation technologies. The aim of mobile- health and telemedicine is to improve the excellence, performance and cost of healthcare by way of digital manner. Therefore, the execution of IoT would work in favour of entrepreneur just as the purchasers. This review paper afford a top level view of the emergence of IoT in healthcare.
\end{abstract}

Keywords: Telemedicine, IoT, IoMT, Technology, Patient Monitoring, Medical.

\section{INTRODUCTION}

IoT is turning out to be fundamental in day to day lives; such as the control of diverse wellbeing and scientific wishes. IoMT is suggested to decrease the effort in observing, informing and telling patients with health updates ${ }^{[10]}$. Moreover, it is able to offer medical doctors with actual facts to be picked out and acknowledge the assets of scientific issues.

Telemedicine lets in medical leverage data technology, telecommunication and video imaging linkages to permit medical assistance and to provide healthcare services at remote places ${ }^{[23]}$. IoT has the capacity to create new efficiencies wherein they've never before existed. All far flung healthcare structures are made accessible to use the net of things as a stage, it may be as simple as estimating the blood pressure of an affected individual and that would be liable for sending reports on special organs inside the body or even on an implanted organ for tracking purpose ${ }^{[12]}$.

\section{IOT HEALTHCARE NETWORKS}

IoT in medical service mentions to a organization of connected clinical gadgets that can be able to generate, collect and keep statistics however additionally hook up with a network, analyse the records and in addition it is capable of transmitting records of numerous types which includes medical images, physiological and crucial body $\operatorname{signs}^{[1]}$.

They are helpful in a few environmental conditions, varying from distant checking to the management of hospitalized patient ${ }^{[4]}$. Perhaps, on every occasion, a patient is in an extreme scientific situation and should be given utmost importance to preserve and manipulate his/her status continuously by tracking some important compounds and parameters ${ }^{[2]}$.

Furthermore, statistics sharing on cloud gadget is also permitting a couple of users, geologically distant from each other, to approach statistics and facts whenever and from wherever as shown in Figure1. This will be useful particularly in rural regions of countries that are still under-evolved where there is a deficient wide variety of experts in fitness-care administration. 


\section{International Journal of Innovative Research in Electrical, Electronics, Instrumentation and Control Engineering}

Vol. 9, Issue 10, October 2021

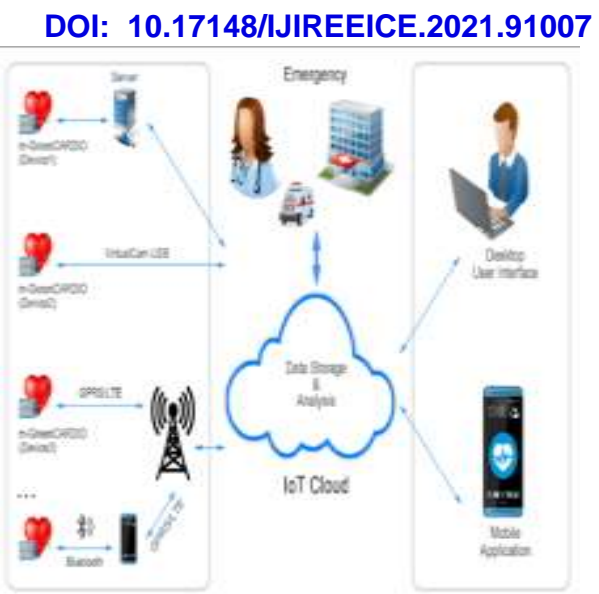

Fig 1: IoT based ECG Monitoring network (Source: https://www.researchgate.net/figure).

\section{NEED FOR TELEMEDICINE}

With the growing call for within the healthcare industry, telemedicine is gaining extra popularity ${ }^{[1]}$. Telemedicine affords affected person's protection, as well as medical experts' safety especially in conditions where there is a threat of contagious infections. There are number of technologies that may be used in telemedicine, which can assist patients with medicinal drug regimens and control their disease better ${ }^{[5]}$. With the telemedicine era, it might be easier for the patients to arrive at the medical services suppliers distantly. This additionally has consequences in raised fatalities and more decay of the influenced individual's wellbeing ${ }^{[6]}$. Apart from this, sanatorium prices and in-character session fees additionally has heavy expenses. For this reason, it might presently be right to mention that telehealth innovation looks forward to have revolution in rural villages of developing and under-developed international locations.

\section{EVOLUTION OF TELEMEDICINE}

In 1940s, Telehealth began to transmit the radiology pictures between two towns that framed the reason for making the Telehealth stage. In 1950, Canadian researcher dealt with the idea and made the principal sharing center point for the city of Montreal which slowly transformed into utilizing tele-conference in emergency clinics for talking about ill person's issues just as distant medical procedure direction from specialists in the field ${ }^{[22]}$.

Something that can empower Telemedicine is the joining of the Web of things which permits distant wellbeing checking through peripherals people wear similar as wellness bands, pulse sensors, and gadgets which keep up with, and transmit updates on any artificially implanted organ inside the human body ${ }^{[14]}$.

There exist numerous hindrances that should be crushed before Telehealth can be generally deployed. As of now, in the US, an expert needs to secure license in every state in which they plan to endorse medications and attend patients. Keen IoT arrangements can successfully satisfy this need by ensuring an online ceaseless association between the patient and the clinical trained professional.

Table II sums up the features of some recently developed portable well being monitoring systems. It is apparent that larger part of the IoT arrangements are accommodated in monitoring elder individuals at home, yet at the same time no develop framework has been proposed for clinic practices.

TABLE 2: COMPARISON BETWEEN SOME IOT SOLUTIONS IN HEALTH MONITOR

\begin{tabular}{|l|l|l|l|l|}
\hline $\begin{array}{l}\text { MEDICAL } \\
\text { APPPLICATION }\end{array}$ & ARCHITECTURE & CLOUD & $\begin{array}{l}\text { FULL } \\
\text { SYSTEM }\end{array}$ & $\begin{array}{l}\text { HOSPITAL } \\
\text { HOME } \\
\text { MONITORING }\end{array}$ \\
\hline $\begin{array}{l}\text { Monitoring the elder } \\
\text { patient health }\end{array}$ & $\begin{array}{l}\text { ECG, Cloud storage } \\
\text { provider, Mobile application }\end{array}$ & Required & Required & Monitored in Home \\
\hline Medical Imaging & $\begin{array}{l}\text { Device for Medical imaging, } \\
\text { Cloud }\end{array}$ & Required & $\begin{array}{l}\text { Not } \\
\text { Required }\end{array}$ & $\begin{array}{l}\text { Monitored } \\
\text { Hospital }\end{array}$ \\
\hline ECG monitor & $\begin{array}{l}\text { ECG, Cloud storage } \\
\text { provider, Mobile application, } \\
\text { Computer software }\end{array}$ & Required & Required & Monitored in Home \\
\hline Anesthesia monitor & Smart watch, Mobile & Not & Required & Monitored in \\
\hline
\end{tabular}


International Journal of Innovative Research in

Electrical, Electronics, Instrumentation and Control Engineering

Vol. 9, Issue 10, October 2021

DOI: 10.17148/IJIREEICE.2021.91007

\begin{tabular}{|l|l|l|l|l|}
\hline & application and TDM system & Required & & Hospital \\
\hline Anesthesia monitor & $\begin{array}{l}\text { Smart watch, Mobile } \\
\text { application, Web app, TDM } \\
\text { system, PRYV middleware } \\
\text { cloud }\end{array}$ & Required & Required & $\begin{array}{l}\text { Monitored Hospital } \\
\text { Hod }\end{array}$ \\
\hline
\end{tabular}

\section{NETWORK ARCHITECTURE}

This segment examines the community version and its interface. Telemedicine is a platform which associates numerous sufferers with innumerable medicinal practitioners through server. The gadget consists of two GUI (Graphical user Interface); one for the physician and the alternative for the affected person. The medical practitioner's GUI enables them to screen the health of the patient and exhort them through a notice with the appropriate therapeutic medication that they can get. This gadget includes databases; one for the clinical specialist and the other for the sufferers where many patients may be tested through the gadget and in which many doctors are available ${ }^{[21]}$. Additionally, each row in the machine's database table addresses a meeting between a health practitioner and affected person who will be robotically coordinated if the affected person's consultation is accessible and may be taken care through a health practitioner whilst each of them are both online or offline. This architecture projects to let the database engine manage which physician will contact which affected person. This is carried out through the assist of C++ programming. For simplicity, this system was made as a portal for each medical practitioners and affected persons with slight dissimilarities inside the program primarily based at the person selected function. The affected person's portal takes the entry facts from a keyboard, web cam and clinical equipments as a way to measure the vitals of the affected person ${ }^{[13]}$. This system then transmits all the record over the cloud to the database server to get stored and make it equipped for the medical doctors to get entry to.

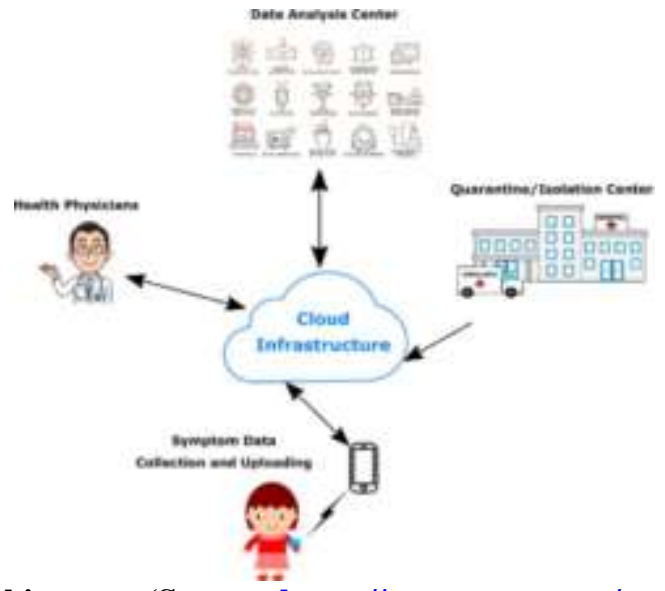

Fig 3: Network Architecture (Source: https://europepmc.org/article/med/32834831)

\section{IMPLEMENTATION OF THE NETWORK}

The organization model is carried out over three remote communication advances: Bluetooth, GSM and Wi-Fi with four distinct clinical fundamental vitals that can be estimated by temperature, heart rate, gas sensor and humidity. The Wi-Fi module is utilized to communicate the information gathered from humidity sensor. The Bluetooth and GSM modules are utilized to associate the pulse sensor. GSM module is associated with temperature and gas sensor ${ }^{[18]}$.

\section{BENEFITS OF IOT IN TELEMEDICINE}

\subsection{Decreased errors}

IoT allows correct series of statistics, automatic workflows and minimised waste, however most significantly it reduces the threat of mistakes.

\subsection{Reduced fees}

With IoT, affected person tracking can be achieved in real-time, notably slicing down the need for medical doctors going out and making visits. Connected home care facilities will even help lessen health centre stays and re-admissions. 


\section{International Journal of Innovative Research in \\ Electrical, Electronics, Instrumentation and Control Engineering}

Vol. 9, Issue 10, October 2021

DOI: $10.17148 /$ IJIREEICE.2021.91007

\subsection{Better affected person experience}

A connected healthcare machine creates surroundings that meet each patient's desires, dedicated procedures, better treatment options and advanced analysis accuracy for a better patient experience.

\subsection{Progressed disease management}

With actual-time statistics, healthcare companies can continuously display patients which mean that they are able to spot any sickness before it spreads and becomes fatal.

\subsection{Homecare}

M2M [Machine to Machine Communication] permits patients to be monitored inside the comfort of their own houses. Sensors are established onto diverse pieces of clinical apparatus (e.g. heart rate monitors) by the bedside of an affected person. The data collected is dispatched to the health facility in which a certified member of group of workers analyse it for any abnormalities ${ }^{[17]}$.

\section{EXECUTION OF IOT IN TELEMEDICINE}

While executing IoT in e-medicine, there are sure viewpoints considered for progress. The vital parts of this implementation are:

\subsection{Deployment area}

IoT gadgets in telehealth are introduced at distant customer place or influenced individual's home. Along these lines, it is protected to investigate the site on the web or the arrangement region. Data of IOT contraptions and its similarity with different gadgets can prompt misleading gadget establishment plan.

\subsection{Gadget operability and evaluation}

It is required to examine the field condition and check for the legitimate operability of the IoT gadget.

\subsection{Security}

IoT in telemedicine typically deals with broadcast communications and web associations. In this manner, it is extremely important to have a safe association, especially for Patient Identity Information (PII) and Patient Health Information (PHI).

\subsection{Maintenance and Webpage preparation}

With inaccurate utilization or with the progression of time, the IoT gadget gets worn off and calls for protection and the clients play a fundamental capacity inside the implementation of IoT online website as far as availability is worried.

\section{TRENDING USES OF TELEMEDICINE}

\subsection{Remote Patient Checking}

The whole idea is to decrease the medical clinic stay, patient visits and the overall medical care use. It is useful for patients who can't achieve the actual help on account of significant distance, awful wellbeing or old age. As an instance; a medical service organization has enhanced a far away diabetes following machine, which continually screens the glucose level in the influenced individual in the wake of being embedded in their arm. The vitals can be really checked through the application introduced in their mobile.

\subsection{Mobile wellbeing}

The innovation is incorporated with hand-held gadget which can be associated with the mobile application downloaded on the patient's smart phone. The gadget assists with controlling a few basic circumstances where the patient requires prompt treatment.

\subsection{Ingestible sensors/gadgets}

An ingestible sensor (as found in Figure 4) travels inside the human body and stays in a specific spot. It can calculate the dosages missed and taken dependent on the detector. Those brilliant medications moreover help to reduce the silly utilization of drugs which can be lethal or hazardous. Those ingestible gadgets in their high level model are to be held with computerized video equipment connected to them that gives the inward perspective on the human body segments and internal organ ${ }^{[19]}$. 
International Journal of Innovative Research in

Electrical, Electronics, Instrumentation and Control Engineering

Vol. 9, Issue 10, October 2021

DOI: $10.17148 /$ IJIREEICE.2021.91007

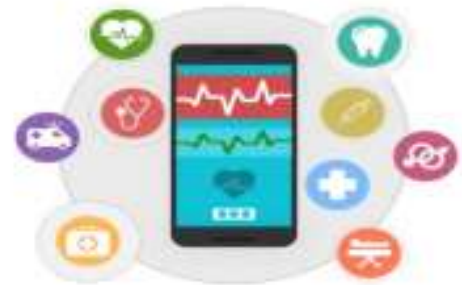

Fig 4: Mobile health(Source: https://www.biospectrumindia.com)

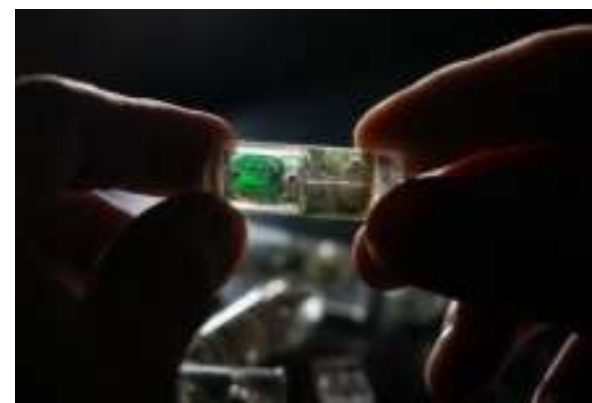

Fig 5: Ingestible device

(Source: https://physicsworld.com/wp-content/uploads/2018/05/flash-gut-sensor.jpg)

\section{IMPORTANCE OF TELEMEDICINE DURING COVID}

All through this overall pandemic, telehealth is arising as an effective and practical response for precautionary measure, anticipation and treatment to stem the unfold of Corona virus ${ }^{[8]}$. The key troubles confronted by the way of health care across countries include, get right of entry to equity, pleasant and esteem viability. Age of telemedicine has flawless capacity to help address all type of concerns ${ }^{[9]}$. It is connecting the distance among individuals, doctors and wellbeing frameworks, allowing everyone particularly suggestive victims, to live at home and speak with doctors through virtual channels, helping to decrease the spread of the infection to mass populace just as the clinical gathering of healthcare workers at the frontlines. It is also vital to keep scant assets like Public Protective Equipment. Telemedicine also plays a vital part in screening Corona virus signs and turning in conventional desires and observe the health condition. Worldwide wellness association has cited telemedicine among its tips for significant administrations in strengthening the wellness to Corona virus coverage ${ }^{[24]}$.

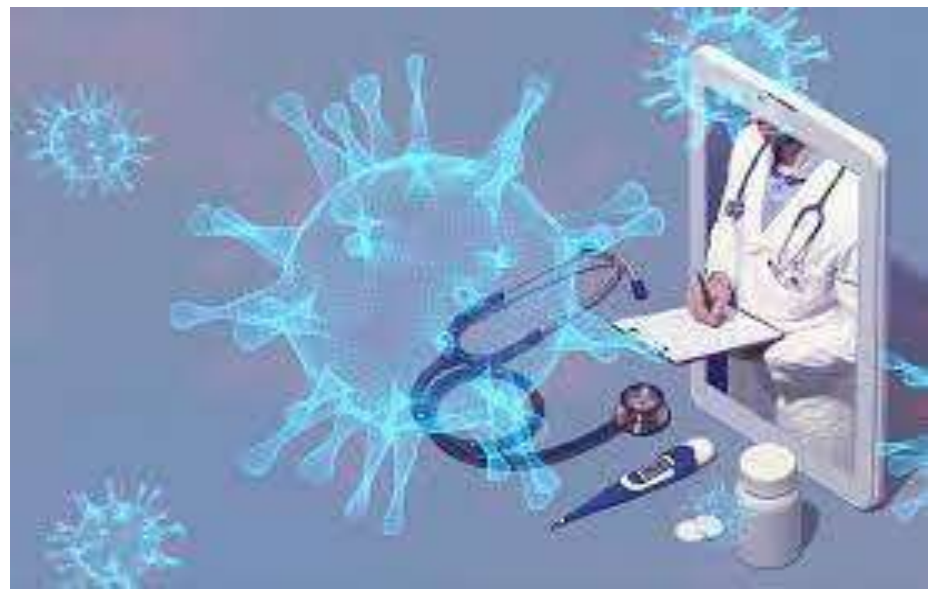

Fig 6: Telemedicine during COVID (Source:https://www.acc.org//-/media/NonClinical/Images/2020/04/13/COVID-19-Telehealth-1200x800.jpg) 


\section{International Journal of Innovative Research in \\ Electrical, Electronics, Instrumentation and Control Engineering}

Vol. 9, Issue 10, October 2021

DOI: 10.17148/IJIREEICE.2021.91007

11. DRAWBACKS AND ADVANTAGES

\subsection{Drawbacks}

On the off chance that the machine doesn't have an amazing assurance, it could permit programmers and hackers to get entrance to the specialist or patient's details and see some hardhearted objective. If the centralized machine or even a solitary influenced individual report is hacked, the entirety of the records can be a benefit for the hackers to abuse and it might likewise lead the total device hacking, this will be extremely unpredictable from the investment inside the medical services industry and could influence the patient's cure as well. While systems get hacked, lots of attention will need to be centred on facts protection, which requires great extra spending. Worldwide health administrations are already issuing guidelines that have to be strictly followed by means of governmental medical establishments ${ }^{[20]}$.

\subsection{Advantages}

The sufferers have no need to go to the health facility as medical doctors can view all the important statistics on command and take a look at it, also reduces the no-show costs because of busy life, awful climate, poor fitness and so on. The era comes with several advantages and it also decreases the investment. One of the principal and finest advantages of IoT in healthcare is that green self sufficient structures will cost much less to control and appoint ultimately. Things are even higher in terms of affected person fee savings due to fewer hospital trips and improved diagnostics as well as remedy. The technology does no longer affect the convenience of the patient to get right of entry to the healthcare centres from remote regions. It additionally offers the specialists adaptability of working and treating patients distantly, without being available in the centers. The IoMT gives space for first rate lengthy-term improvements ${ }^{[16]}$.

\section{CONCLUSION}

As the most recent advancements continue to get presented in the medical services area, the IoT in telemedicine is additionally predicted to observe significant development ${ }^{[25]}$. This review work proposed a stage that could be embraced where the ill persons can reach out to one of the specialists distantly. Telemedicine is a thrilling innovation and keeps on holding the guarantee of being genuinely transformational as far as medical services delivery to everybody's advantage. As the populace keeps on developing at a quicker rate than the accompanying development in the quantity of accessible qualified clinicians and offices (institutional beds, examination labs, day-care focuses, and so on), this innovation should ideally guarantee that every one of the individuals who need care are taken into account essentially at adequate levels, if not the most ideal ${ }^{[15]}$. Telemedicine will work on both communication and levels of fulfilment. This will assist with tending to a large number of the issues that right now challenge the situation. The patient burden in the offices will descend, and clinicians should travel less and have the option to commit additional time and exertion on those patients who really need such consideration.

\section{REFERENCES}

1. S.M.Raizul Islam, Daehan Kwak, Md Humaun Kabir, Mahmud Hossain- The Internet of Things for Health Care: A Comprehensive Survey-June 2015-IEEE Access 3:678-708-DOI:10.1109/ACCESS.2015.2437951

2. Kamta Nath Mishra, Chinmay Chakraborty- A Novel Approach Towards Using Big Data and IoT for Improving the Efficiency of m-Health Systems- 12 December 2019

3. Chinmay Chakraborty, Bharat Gupta, and Soumya K. Ghosh, -A Review on Telemedicine-Based WBAN Framework for Patient Monitoring-

4. Sultan Almotiri, Murtzara khan, Mohammed A.Alghmadi-Mobile Health (m-Health) System in the Context of IoT-August 2016DOI: 10.1109/W-FiCloud.2016.24

5. Antonio J.Jara, Miguel A.Zamora Izquierdo, Antonio Skarmeta-Knowledge Acquisition and Management Architecture for Mobile and Personal Health Environments Based on the Internet of Things-June 2012-DOI:10.1109/TrustCom.2012.194

6. Umar Albalawi, Department of Computer Science and Engineering, University of Tabuk, KSA.Shital Joshi, Department of Computer Science and Engineering, Oakland University,- Secure and trusted telemedicine in Internet of Things IoT -USA-INSPEC Accession Number: 17738001DOI: 10.1109/WF-IoT.2018.8355206-07 May 2018

7. Shuo-Jen Hsu, Hsin-Hsien Wu, Shih-Wei Chen, Tsang-Chi Liu-Development of Telemedicine and Telecare over Wireless Sensor Network-Date Added to IEEE Xplore: 07 May 2008-Print ISBN: 978-0-7695-3134-2-INSPEC Accession Number: 9962810-DOI: 10.1109/MUE.2008.105

8. Satya Prakash Dash- The Impact of IoT in Healthcare: Global Technological Change \& the Roadmap to a Networked Architecture in India 03 November 2020

9. Suneela Garg, Navya Gangadharan, Nidhi Bhatnagar, MM Singh, SK Raina, Sagar Galwankar - Telemedicine: Embracing virtual care during COVID-19 pandemic-Year : 2020 -Volume : 9 -Issue : 9 -Page : 4516-4520

10. Manjit Singh, FIETE -Internet of Medical Things: Advent of Digital Doctor

11. Prof. Valentin sinitsyn- The Future of Telemedicine: Two Perspectives- Volume 16 - Issue 4, 2016

12. Salah Al-Majeed, Intisar S.Al-Mejibli,Jalal Karam-Home telehealth by Internet of Things (IoT)- Date Added to IEEE Xplore: 25 June 2015-Print ISSN: 0840-7789-INSPEC Accession Number: 15239745-DOI: 10.1109/CCECE.2015.7129344. 


\section{International Journal of Innovative Research in Electrical, Electronics, Instrumentation and Control Engineering}

\section{Vol. 9, Issue 10, October 2021}

\section{DOI: $10.17148 /$ IJIREEICE.2021.91007}

13. Francesca Stradolini, Nadia Tamburrano, Thiebaud Modoux, Danilo Demarchi, Sandro Carrara, Aduduwaili Tuoheti-IOT for Telemedicine: Practices enabled by an Android Application with Cloud System Integration-May 2018-DOI:10.1109/ISCAS.2018.8351871.

14. Mohammad Mahmoud Abdellatif, Walaa Mohamed- Telemedicine: An IOT based remote healthcare system- DOI:10.3991/ijoe.v16i06.13651

15. Mohd Javaid and Ibrahim Haleem Khan- Internet of Things (IOT) enabled healthcare helps to take the challenges of COVID-19 Pandemic- 2021 January 30-DOI:10.1016/j.jpbcr.2021.01.015

16. M Krol-Telemedicine-Journals \& Magazines-IEEE Potentials-Volume: 16 -Issue: 4

17. Minesh Ade, Nikolaos Doulamis, Shyam S Wagle, and M Ghazanfar Ullah- Telehealth: Healthcare technologies and telehealth emergency system-INSPEC Accession Number: 12094534- DOI:10.1109/WIRELESSVITAE.2011.5940870- 05 July 2011

18. Pranit Pol, Ashwini M Deshpande- Telemedicine mobile system-INSPEC Accession Number: 1648250- DOI:10.1109/CASP.2016.7746220- 17 November 2016

19. Amin Moghadas, Mo Jamshidi, Mehdi Shaderam- Telemedicine in healthcare system-INSPEC Accession Number: 10411801- ISSN: 2154-4824 -09 December 2008

20. Nils Magnus Hjelm- Benefits and drawbacks of telemedicine- February 2005- DOI: 10.1258/1357633053499886

21. Jaimon T Kelly, Katrina L Campbell, Enying Gong, Paul Scuffham-The Internet of Things: Impact and Implications for healthcare delivery.

22. Hamidreza Shirzadfar, Fatemeh Lotf -Evolution and Current Applications of Telemedicine- International Journal of Biosensors \& Bioelectronics- Volume 3, Issue 4-2017.

23. Fawwaz E. Fajingbesi, Rashidah F. Olanrewaju, Bisma Rasool Pampori, Sheroz Khan, Mashkuri Yacoob -Real Time Telemedical Health Care Systems with Wearable Sensors- Asian Journal of Pharmaceutical Research and Health Care- Volume 9, Issue 3, 2017

24. Nikhil Bhalla, Yuwei Pan, Zhugen Yang and Amir Farokh Payam- Opportunities and Challenges for Biosensors and Nanoscale Analytical Tools for Pandemics: COVID-19-ACS Publications- Date: June 18, 2020.

25. Aarohi Desai-The Future of Healthcare: IoT, Telemedicine, Robots \& Artificial Intelligence- May 31, 2021. 